\title{
DETERMINAÇÃO DE INDICADORES DE DESEMPENHO AMBIENTAL PARA AS INDÚSTRIAS SUCROALCOOLEIRAS
}

\section{DETERMINATION OF ENVIRONMENTAL PERFORMANCE INDICATORS FOR SUGARCANE INDUSTRY}

\author{
Fabiana Raupp ${ }^{1}$; Paulo Maurício Selig ${ }^{2}$; Eduardo Juan Soriano-Sierra ${ }^{3}$ \\ ${ }^{1}$ Universidade Federal da Grande Dourados - UFGD - Itahum - MS - Brasil \\ fabianaraupp@gmail.com \\ ${ }^{2}$ Universidade Federal de Santa Catarina - UFSC - Florianópolis - SC - Brasil \\ pauloselig@gmail.com \\ ${ }^{3}$ Universidade Federal de Santa Catarina - UFSC - Florianópolis - SC - Brasil \\ sierra_ejs@yahoo.com.br
}

\section{Resumo}

A relação das empresas com o meio ambiente tem mostrado que os impactos ambientais resultantes das atividades produtivas estão comprometendo o futuro do planeta. A forma como as empresas veem as questões ambientais e planejam seu desenvolvimento é de extrema importância para a sua sobrevivência e a conservação do meio ambiente. O setor sucroalcooleiro é reconhecido como sendo um dentre os mais impactantes sobre o meio ambiente. Assim, o objetivo deste trabalho é propor indicadores de desempenho ambiental que possam ser aplicados nas indústrias sucroalcooleiras. Para isso foi realizado um levantamento bibliográfico e bibliométrico dos principais indicadores de desempenho ambiental e após um cruzamento entre eles para verificar pontos de convergência. Num segundo momento foi elaborado um questionário que foi encaminhado para as empresas, com os indicadores selecionados, para que eles verificassem sua aplicabilidade no setor. Com a resposta obtida foram determinados os indicadores de desempenho ambiental para as indústrias sucroalcooleiras.

Palavras-chave: Avaliação de Desempenho Ambiental. Indicadores de Desempenho Ambiental. Indústria Sucroalcooleira.

\section{Introdução}

A proteção ambiental deixou de ser uma questão exclusiva da produção para tornar-se uma questão gerencial nas empresas, passando a ser contemplada na estrutura organizacional e interferindo no planejamento estratégico. Desta forma se tornando uma atividade importante na organização da empresa, sendo considerada nas atividades rotineiras, na discussão dos cenários alternativos e na consequente análise de sua evolução, até na geração de políticas, metas e planos de ação. É nesse momento que a preocupação com o meio ambiente torna-se um valor da empresa, como um dos objetivos principais a ser perseguido pelas organizações (DONAIRE, 1999). 
O setor sucroalcooleiro está consciente de sua necessidade de mudança para conseguir integrar homem e meio ambiente. Como questões para ações concretas e relevantes, podem-se citar (UDOP, 2010; ÚNICA, 2008):

- Emissões de gases de impacto global;

- Uso de recursos hídricos;

- Disposição de efluentes;

- Uso de defensivos agrícolas;

- Mudança do uso da terra e desmatamento da Amazônia.

Conforme Sabadin e Gonçalves (2005), os impactos ambientais ligados à atividade canavieira ainda não foram amplamente estudados, mas os principais problemas estão relacionados à queima da palha da cana, que gera os gases de efeito estufa.

Manfinato e Rocha (2010) afirmam que é necessário que o setor sucroalcooleiro perceba a importância da questão ambiental e a sua utilidade, tanto do ponto de vista de uma proteção dos recursos para uma agricultura sustentável, quanto para do ponto de vista dos países potencialmente compradores do álcool brasileiro.

Neves (2009) corrobora dizendo que nessa nova ótica da sustentabilidade, todos os agentes, do sistema agroindustrial da cana, em conjunto com governos e sociedade, precisam divulgar a imagem sustentável do álcool brasileiro perante o mundo, com uma afirmação de imagem do combustível limpo e a valorização do produto nacional. Para ele, deve-se focar nos seguintes itens ao divulgar o combustível brasileiro:

- Reduz a dependência dos países com relação ao petróleo importado e escasso;

- Estimula a adoção de tecnologias limpas;

- Garante um sistema de produção sustentável, com balanço energético elevado;

- Permite a cogeração de energia limpa;

- Gera créditos de carbono;

- Promove a inclusão de pequenos agricultores com remuneração adequada;

- Tem capacidade de honrar contratos de longo prazo.

Essa tendência da busca pela sustentabilidade das indústrias do setor sucroalcooleiro já pode ser verificada através do Protocolo Verde no Estado de São Paulo, ou Protocolo Agro Ambiental, firmado com o Governo de São Paulo em 2007. Neste, a indústria canavieira do Estado se compromete a antecipar a eliminação da prática tradicional da queima da cana para posterior colheita, pela colheita mecanizada, de 2021 para 2014 (UNICA, 2008). 
Conforme este Protocolo, pode-se verificar 10 cláusulas que os produtores e a indústria de cana-de-açúcar devem atender, sendo estas a eliminação da queimada durante a colheita, a proteção da mata ciliar e das nascentes de água das áreas rurais do empreendimento, a implementação do Plano Técnico de Conservação do Solo, o Plano Técnico de Conservação de Recursos Hídricos, as práticas de descarte de embalagens vazias de agrotóxico e a adoção de boas práticas destinadas a minimizar a poluição atmosférica de processos industriais e otimizar a reciclagem e o reuso adequado dos resíduos gerados na produção de açúcar e etanol.

Desta forma, este trabalho visa contribuir para integração do conceito de desempenho ambiental ao processo de produção da indústria sucroalcooleira, já que se entende que muito mais pode ser feito para melhorar o desempenho ambiental da indústria do que apenas adotar boas práticas destinadas a minimizar a poluição atmosférica de processos industriais e das queimadas e otimizar a reciclagem e o reuso adequado dos resíduos gerados na produção de açúcar e etanol.

Este trabalho tem como objetivo desenvolver um modelo de autoavaliação de desempenho ambiental que preserve as características das agroindústrias, em especial das indústrias sucroalcooleiras, já que conforme Girardin, et al (2000), há uma necessidade muito grande de ferramentas de avaliação dos efeitos ambientais para a agricultura.

\section{Gestão ambiental}

De acordo com Lora (2000), Donato (2008) e Esty (2008), a questão ambiental deve ser considerada um elemento a mais da competitividade, pois não é possível falar de qualidade total pensando somente na qualidade intrínseca do produto, sem considerar a qualidade ambiental.

Para Esty (2008), a análise da questão ambiental precisa ser incorporada ao planejamento estratégico da empresa, e que desta forma podem-se evitar problemas de alto custo e criar valor nos produtos. Para ele as empresas que sairão na frente serão as que conseguirem encontrar soluções para o aquecimento global, escassez de água, extinção de espécies, sinais da presença de substâncias tóxicas nos seres humanos e animais, entre outras que afetam o funcionamento da empresa.

Para que as organizações industriais se tornem conscientes e reajam, Lerípio (2001) diz que existem dois tipos de pressões que são exercidas sobre elas: as pressões perceptíveis, que são aquelas que afetam diretamente as organizações e, portanto são prioritárias e estratégicas dentro de seu planejamento, tais como competitividade, saúde e segurança no trabalho, legislação, fornecedores, clientes e opinião pública; e as pressões não perceptíveis, que são aquelas que não são (ou não eram) tratadas como prioridades, embora também afetem diretamente a organização ou as partes interessadas, como biodiversidade, efeito estufa, resíduos industriais, redução de recursos naturais etc. 
Para que as empresas tenham conhecimento do seu desempenho ambiental, atualmente existem vários indicadores que podem ser utilizados, como será apresentado a seguir. Além destes indicadores, para que as empresas evitem alguns impactos negativos, e que as empresas possam exercer suas atividades, atualmente as empresas precisam apresentar ao órgão ambiental um Estudo de Impacto Ambiental e o Relatório de Impacto Ambiental (EIA/RIMA) de suas atividades.

\subsection{Indicadores de desempenho ambiental}

A falta de ferramentas que permitam avaliar o risco e a dependência que as empresas têm dos serviços ambientais é um problema, por isso o objetivo dos indicadores é agregar e quantificar informações para mostrar a sua importância. Eles simplificam as informações sobre fatos complexos tentando melhorar com isso o processo de comunicação.

Para Van Bellen (2006), o objetivo da mensuração é auxiliar os tomadores de decisão na avaliação do desempenho em relação aos objetivos estabelecidos, fornecendo bases para o planejamento de futuras ações. Para isso, eles precisam de ferramentas que conectem atividades passadas e presentes com as metas futuras, e os indicadores são o seu elemento central.

Outro fator que deve ser levado em consideração é a finalidade dos indicadores. Eles servem para medir o grau de sucesso da implantação de uma estratégia em relação ao alcance do objetivo estabelecido. Entretanto, é fundamental que seja observado o fato de que "... um indicador muito complexo ou de difícil mensuração não é adequado, pois o custo para sua obtenção pode inviabilizar a sua operacionalização" (CORAL, 2002, p.159).

Hronec (1994) cita alguns benefícios das medidas de desempenho: satisfação dos clientes; monitoramento do processo; benchmarking de processos e atividades, respectivamente; e a geração de mudanças. Mas que para esses benefícios sejam alcançados é necessário que as medidas de desempenho estejam corretas para haver a mudança com sucesso.

Os indicadores de desempenho ambiental visam demonstrar as práticas organizacionais no sentido de minimizar os impactos ao meio ambiente decorrentes de suas atividades. Esses indicadores referem-se ao uso de recursos naturais demonstrados em valores monetários e em valores absolutos de quantidade ou consumo, considerando também as iniciativas de gerenciamento ambiental, os impactos significativos relacionados ao setor da atividade e as respectivas ações de minimização (GASPARINI, 2003).

Assim, conforme Strobel (2004), a tarefa de mensurar a sustentabilidade de uma sociedade, de uma comunidade ou de uma organização não é simples nem tampouco estanque. A definição de indicadores adequados a esta meta deve ser estudada a fundo e, uma vez estabelecida, deve ser flexível o suficiente para que o conjunto de indicadores seja alterado na medida em que a realidade 
o permita e necessite. A atualização dos indicadores é possível e desejada, desde que tenha como consequência uma visão cada vez mais realista do status da sustentabilidade.

Conforme Gallardo e Bond (2010), várias ferramentas ambientais têm sido identificadas para avaliar a sustentabilidade no setor de bioenergia, como Análise de Ciclo de Vida - ACV (Life Cycle Analysis - LCA), Avaliação de Impacto Ambiental (Environmental Impact Assessment - EIA) e Avaliação Ambiental Estratégica (Strategic Environmental Assessment - SEA) ou Avaliação da Sustentabilidade (Sustainability Assessment - SA), que também podem fazer contribuições valiosas para a avaliação dos impactos do crescimento e produção de biocombustíveis, devido à interação de múltiplos fatores.

O EIA (Estudo de Impacto Ambiental) já é exigido como base para a tomada de decisões para projetos relacionados a cana-de-açúcar no Brasil e, consequentemente, seu desempenho na identificação impactos é uma questão fundamental.

Outros indicadores são aplicados como o Global Reporting Initiative - GRI, que surgiu para melhorar os relatórios de sustentabilidade corporativa, o Dow Jones Sustainability Index, que acompanha o desempenho financeiro das empresas líderes em sustentabilidade corporativa, através dos indicadores econômicos, ambientais e sociais. Além destes tem-se os indicadores ambientais da OECD, Indicadores MAIS, o Método GAIA, os Princípios de Valdez (CERES), os indicadores da Agência Proteção Ambiental Americana (Environmental Protection Agency, US - EPA), e a ISO 14031 que trata da Avaliação de Desempenho Ambiental que podem auxiliar as empresas nesta busca.

\subsubsection{Indicadores ambientais da OECD}

A Organização para Cooperação Econômica e Desenvolvimento (OECD) publica indicadores ambientais desde 1991. O objetivo é medir o desempenho e o progresso na questão ambiental; monitorar e promover políticas de integração e promover a integração de conceitos ambientais em políticas econômicas de diversas nações (OECD, 2008). Seus principais indicadores ambientais são:

- Mudanças do clima: Avalia índices de emissão de gases de efeito estufa.

- Camada de ozônio: Avalia índices de aparente consumo de substâncias que destroem a camada de ozônio em alta atmosfera.

- Qualidade do ar: São os índices de emissão de óxidos de nitrogênio $\left(\mathrm{NO}_{\mathrm{x}}\right)$ e enxofre $\left(\mathrm{SO}_{\mathrm{x}}\right)$, concentração de chuva ácida, quantidade de catalisadores por frota de um local e/ou eficiência dos mesmos, relação entre a densidade demográfica e quantidade de carros e quantidade de pessoas que estão expostas à poluição do ar. 
- Geração de resíduos: Refere-se à geração de resíduos domiciliares, industriais, perigosos e nucleares e seus efeitos sobre a qualidade da água, so solo e ar. Verifica a taxa de reciclagem e a minimização de resíduos.

- Qualidade da água doce: Avalia índices de emissão de nitrogênio e fósforo para o solo e a água por parte de atividades agroindustriais, contaminação tóxica por metais pesados e compostos orgânicos e pH da água.

- Recursos de água doce: Intensidade de utilização dos recursos da água doce, bem como frequência, duração e extensão da falta de água e tarifas de utilização deste recurso.

- Recursos florestais: Avalia a intensidade de utilização de recursos florestais.

- Recursos pesqueiros: São avaliados pela captura de peixes, por meio do tamanho do estoque para desova em áreas destinadas e pelo estabelecimento de cotas de pesca e despesas para acompanhamento do estoque.

- Recursos energéticos: São medidos por eficiência e intensidade energética, utilização de combustível fóssil e instrumentos econômicos e fiscais.

- Biodiversidade: É mensurada pelo número de espécies ameaçadas comparado com o numero de espécies conhecidas avaliadas.

\subsubsection{Princípios CERES}

Os Princípios CERES (Coalizão para Economias Ambientalmente Responsáveis) consistem em dez diretrizes de ética para que investidores e outras partes interessadas possam avaliar o desempenho ambiental de empresas (CERES, 2009). Foram criados em 1989, a partir do acidente ambiental com derramamento de petróleo no Alasca (EUA), envolvendo o navio Exxon Valdez:

- Proteção da biosfera: reduzir a liberação de qualquer substância que possa causar danos ao ar, à água, à terra ou aos habitantes, e proteger todos os habitats afetados por operações.

- Uso sustentável dos recursos naturais: utilizar de forma sustentável os recursos naturais renováveis, como água, terra e florestas.

- Redução e disposição dos resíduos: eliminar ou reduzir a produção de resíduos na fonte e praticar reciclagem.

- Conservação da energia: melhorar a eficiência e a segurança energética de operações internas e dos bens e serviços vendidos.

- Redução de riscos: diminuir riscos ambientais à saúde e segurança dos funcionários e comunidade, através da instalação e procedimentos seguros e preparação para emergências.

- Produtos e serviços seguros: eliminar ou reduzir uso, fabricação ou venda de produtos e serviços que causem danos ambientais ou à saúde. 
- Restauração ambiental/indenização por danos: reparar de forma responsável ou indenizar com relação a causas de perigo para saúde, segurança ou meio ambiente.

- Divulgação de informação ambiental: informar em tempo hábil todos os que possam ter sua saúde ou segurança afetadas por condições provocadas pela empresa e manter diálogo com comunidades.

- Responsabilidade ambiental da alta administração/gestão de compromisso: garantir que a alta administração seja informada sobre questões ambientais e que seja responsável pela política ambiental.

- Realização de auditorias ambientais e relatórios: realizar auto-avaliação anual do progresso na implementação dos Princípios CERES e sua divulgação ao público.

\subsubsection{Indicadores da Global Reporting Initiative (GRI)}

O Global Reporting Initiative (GRI) consiste em uma evolução do CERES promovida por executivos, membros de ONGs e pelo Programa das Nações Unidas para a Proteção Ambiental (UNEP) no final dos anos 90. O objetivo foi tornar mais transparentes relatórios de sustentabilidade corporativa (GRI, 2008). O GRI apresenta um conjunto de protocolos "EN" onde estão apresentados 30 indicadores de desempenho do meio ambiente, divididos em nove aspectos:

- Materiais: avalia materiais usados, por peso ou volume (EN1), e percentual de materiais usados provenientes de reciclagem (EN2).

- Energia: verifica os consumos de energia direta (EN3) e indireta (EN4) discriminados por fonte primária; a energia economizada (EN5), iniciativas para fornecer produtos e serviços com baixo consumo de energia, ou que usem energia gerada por produtos renováveis, e a redução na necessidade de energia resultante dessas iniciativas (EN6); além de iniciativas para reduzir o consumo de energia indireta e as reduções obtidas (EN7).

- Água: avalia o total de retirada de água por fonte (EN8); fontes hídricas significativamente afetadas por retirada de água (EN9); percentual e volume de água reciclada e reutilizada (EN10).

- Biodiversidade: avalia a localização e tamanho da área possuída, arrendada ou administrada dentro de áreas protegidas, ou adjacentes a elas, e áreas de alto índice de biodiversidade fora das áreas protegidas (EN11); descrição de impactos significativos na biodiversidade de atividades, produtos e serviços em áreas protegidas e em áreas de alto índice de biodiversidade fora das áreas protegidas (EN12); habitats protegidos ou restaurados (EN13); estratégias, medidas em vigor e planos futuros para a gestão de impactos na biodiversidade (EN14); 
e número de espécies ameaçadas ou em risco de extinção, segundo critérios internacional e nacionais (EN15).

- Emissões, efluentes e resíduos: considera o total de emissões diretas e indiretas de gases de efeito estufa, por peso (EN16); outras emissões indiretas relevantes de gases causadores do efeito estufa, por peso (EN17); iniciativas para reduzir as emissões de gases causadores do efeito estufa e as reduções obtidas (EN18); emissões de substancias destruidora da camada de ozônio, por peso (EN19); NOx, SOx e outras emissões atmosféricas significativas, por tipo e peso (EN20); descarte total de água, por qualidade e destinação (EN21); peso total de resíduos, por tipo e método de disposição (EN22); número e volume total de derramamentos significativos (EN23); peso de resíduos transportados, importados, exportados ou tratados considerados perigosos nos termos da Convenção da Basiléia - Anexos I, II, III de resíduos transportados internacionalmente (EN24); identificação, tamanho, status de proteção e índice de biodiversidade de corpos d'água e habitats relacionados significativamente afetados pro descartes de água e drenagem realizados pela organização relatora (EN25).

- Produtos e serviços: verifica iniciativas para mitigar os impactos ambientais de produtos e serviços e a extensão da redução desses impactos (EN26); percentual de produtos e suas embalagens recuperados em relação ao total de produtos vendidos, por categoria de produto (EN27).

- Conformidade: avalia o valor monetário de multas significativas e número total de sanções não-monetárias resultantes da não conformidade com leis e regulamentos ambientais (EN28).

- Transporte: verifica os impactos ambientais significativos do transporte de produtos e outros bens e materiais utilizados nas operações da organização, bem como do transporte de trabalhadores (EN 29).

- Geral: verifica o total de investimentos e gastos em proteção ambiental, por tipo (EN 30).

\subsubsection{Agência Proteção Ambiental Americana (Environmental Protection Agency, US - EPA)}

Para medir o desempenho ambiental, a EPA US descreve algumas etapas como a elaboração de um fluxograma do processo que identifique todas as entradas e saídas (EPA US, 2003).

Entradas:

- Recursos materiais: as principais fontes não-químicas utilizados no processo.

- Produtos químicos: todos os materiais químicos utilizados no processo.

- Uso de energia: tipo de energia e uso.

- Uso da Água: tipo de água e uso. 
- Outros Insumos: insumos que não são cobertos nas outras categorias.

Saídas:

- Emissões ar.

- Ruído, odor e radiação oriunda do processo.

- As descargas de água: todos os córregos de águas residuais onde há descarga direta de tempestade ou sistemas de esgotos sanitários ou águas de superfície.

- Resíduos sólidos: todos os materiais destinados a serem descartados ou eliminados, regulamentados ou não, e incluem os líquidos, sólidos e gases.

- As descargas de águas pluviais de todas as áreas de processo.

- Derramamentos que possam ocorrer em todas as áreas de processo.

Ao se elaborarem os diagramas, devem-se fazer anotações de outras informações, como a quantidade ou volume utilizado por unidade de tempo, quando disponíveis.

\subsection{5 Índice Dow Jones de Sustentabilidade (DJSI)}

O DJSI foi o primeiro indicador de sustentabilidade corporativa de nível global criado para acompanhar a performance de empresas líderes em seus campo de atuação em termos de sustentabilidade corporativa de forma global, em 1999 (DOW JONES, 2009).

É uma abordagem que considera dimensões social, econômica e ambiental, assim como o gerenciamento das oportunidades, riscos e custos ligados a ela. É operacionalizado por meio de um questionário de 30 itens. Destes, os seguintes são relacionados à questão ambiental:

- Relatórios ambientais (26)

- Desempenho ambiental (27): é avaliado através da evolução das emissões de gases de efeito estufa, utilização de água, consumo de energia e desperdício total.

- Outros itens aplicáveis: sistemas de gerenciamento ambiental, estratégia climática, impactos sobre a biodiversidade, gestão de produtos.

\subsubsection{Método de Gerenciamento de Aspectos e Impactos Ambientais (GAIA)}

É um conjunto de instrumentos e ferramentas gerenciais com foco no desempenho ambiental que é aplicável aos processos produtivos de uma dada organização (LERÍPIO, 2001). Inclui quatro critérios, divididos em grandes grupos baseados nas principais etapas do ciclo de vida do produto: fornecedores; processo produtivo; utilização do produto; destinação do produto pós-consumido. Cada etapa é abordada por questionamentos: 
- Critério 1: verifica se as matérias-primas são renováveis, se o processo produtivo do fornecedor é impactante, se utiliza muita/pouca energia e se possui certificação ambiental, de saúde e segurança.

- Critério 2: avalia a eco-eficiência do processo produtivo, o nível da tecnologia utilizada no processo, aspectos e impactos ambientais do processo, indicadores gerenciais, recursos humanos na organização e disponibilidade de capital. Para isto, propõe 65 questionamentos sobre estes subitens.

- Critério 3: avalia a utilização do produto/serviço, checando o nível de consciência ambiental do consumidor, a periculosidade do produto, a existência ou não de concorrência, o grau de necessidade em relação ao produto e questões de embalagem, entre outras.

- Critério 4: trata do produto pós-consumido, questionando se ele pode ser reutilizado, se pode ser desmontado, reciclado, se é biodegradável, perigoso, além de outros.

\subsubsection{Método de Avaliação dos Indicadores de Sustentabilidade (MAIS)}

O MAIS tem por objetivo identificar oportunidades para a melhoria contínua por meio da avaliação de aspectos da sustentabilidade. Envolve quatro dimensões: social, ambiental, econômica e cultural (OLIVEIRA, 2002).

No total, são 40 indicadores divididos nas dimensões, cada uma com 10 indicadores avaliados conforme o grau de política ou procedimentos adotados.

Na dimensão de sustentabilidade ambiental do MAIS constam os seguintes itens: política de gestão ambiental; avaliação de aspectos e impactos ambientais do negócio; preparação para emergências; ações corretivas e preventivas; avaliação do desempenho global; avaliação de riscos; avaliação de oportunidades; estratégias para desenvolvimento de tecnologias ecologicamente equilibradas; análise do ciclo de vida de produtos e serviços; controle operacional. No final tem-se a classificação da organização, em insustentável; em busca da sustentabilidade; e sustentável.

\subsubsection{ISO 14031}

De acordo com a ABNT NBR ISO 14031 (2004), esta norma tem como objetivo ser um processo e ferramenta de gestão interna, planejada para prover uma gestão com informações confiáveis e verificáveis, para que se possa determinar se o desempenho ambiental de uma empresa está de acordo com os critérios estabelecidos.

Dentro deste objetivo, a Avaliação do Desempenho Ambiental (ADA) pode auxiliar a organização na identificação dos aspectos ambientais, na determinação dos aspectos significativos, estabelecimento de critérios para o desempenho ambiental e na avaliação do seu desempenho ambiental. A ADA segue um modelo gerencial do PDCA - Plan-Do-Check-Action (Planejar, Fazer, Checar e Agir) (ABNT NBR ISO 14031, 2004) 
Conforme a ABNT NBR ISO 14031 (2004), existem duas categorias gerais de indicadores a serem considerados na Avaliação de Desempenho Ambiental - ADA: Indicador de Condição Ambiental (ICA) e o Indicador de Desempenho Ambiental (IDA).

O IDA, ainda pode ser classificado em Indicador de Desempenho Operacional (IDO) e Indicador de Desempenho de Gestão (IDG) que abordam as seguintes ações:

- Materiais;

- Energia;

- Serviços de apoio as operações da organização;

- Instalações físicas e equipamentos;

- Fornecimento e distribuição;

- Produtos;

- Serviços fornecidos pela organização;

- Resíduos;

- Emissões.

- Implementações de políticas e programas;

- Conformidade;

- Desempenho financeiro;

- Relações com a comunidade.

\subsection{Avaliação do impacto ambiental - AIA na indústria sucroalcooleira}

A expressão "impacto ambiental" é muito difundida, mas muitas vezes sua definição é desconhecida, assim, a ISO 14001 define como sendo: "qualquer modificação do meio ambiente, adversa ou benéfica, que resulte, no todo ou em parte, das atividades, produtos ou serviços de uma organização" (NBR ISO 14.001: 2004). Já a International Association for Impacts Assessment IAIA (1999) define como sendo o processo de identificação, previsão, avaliação e mitigação dos efeitos resultantes de propostas, sendo um passo anterior da aprovação.

Conforme Silva e Ferreira (2009), os principais impactos ambientais do setor sucroalcooleiro diz respeito a diminuição da disponibilidade hídrica decorrente da indução de processos erosivos e da captação superficial de água, a queima da palha da cana-de-açúcar, o descarte inconsciente do vinhoto na natureza a perda da produtividade do solo, da biodiversidade e alterações climáticas.

Trindade e Chaves (2009), Piacente (2005) e Silva e Ferreira (2009) especificam a existência de impactos ambientais do setor sucroalcooleiro dividindo-os em duas categorias: os agrícolas e os industriais. 
Na fase agrícola destaca-se:

- Minimização da biodiversidade em detrimento a substituição da vegetação natural pela monocultura canavieira;

- Emissão de embalagens de agrotóxicos;

- Consumo intenso de óleo diesel, nas etapas de plantio, colheita e transporte;

- Concentração de terras, rendas e condições subumanas do trabalho do cortador de cana;

- Impactos sobre o solo;

- Desmatamentos de matas ciliares;

- Assoreamentos nos rios da região diminuição do volume d'água;

- Queima da palha da cana-de-açúcar;

- Dispersão de fuligens pelos ventos para áreas além da lavoura;

- Aumento de doenças respiratórias nos períodos de queimadas.

$\mathrm{Na}$ fase industrial pode-se relacionar:

- Uso de recursos materiais (principalmente energia e materiais);

- Geração de resíduos potencialmente poluidores como a vinhaça e a torta de filtro;

- Utilização intensiva de água para o processamento industrial da cana de açúcar;

- Forte odor gerado na fase de fermentação e destilação do caldo para a produção de álcool.

A partir disso pode-se perceber uma controvérsia no processo produtivo das indústrias sucroalcooleiras, de um lado ele está diretamente envolvido numa nova forma de energia, ambientalmente correta, e de outro causador dos impactos ambientais apresentados (SILVA E FERREIRA, 2009; TRINDADE E CHAVES, 2009).

\subsection{Comparação entre os indicadores de desempenho ambiental e os impactos apresentados pelos eias e a pesquisa bibliométrica}

Para se obter um conjunto de indicadores que realmente fossem próprios às indústrias sucroalcooleiras, foram utilizados na pesquisa, os Estudos de Impacto Ambiental - EIA`s de duas usinas implantadas no Estado do Mato Grosso do Sul.

Assim, é apresentada a comparação entre os indicadores de desempenho ambiental e os impactos ambientais apresentados pelos EIA`s. Esta comparação foi realizada da maneira como os itens apareciam nas descrições de cada indicador abordado. Em alguns casos o nome não era exatamente o mesmo, mas o significado sim. 
Para dar mais suporte aos indicadores de desempenho ambiental escolhidos para este estudo, foi realizada uma busca sistemática bibliométrica nas principais bases de dados: science direct, scopus, web of science e scielo com as palavras chaves evaluation, environmental, performance e sugarcane, entre os períodos de 1998 e 2012. Encontrou-se mais de mil artigos que foram avaliados, onde restaram 23 que estavam alinhados com o tema do trabalho. Também foi feita uma pesquisa com os autores mais citados com estas palavras chaves, resultando em 3 artigos.

Desta forma, foi criado o quadro 1 que apresenta os autores que também aplicam os critérios levantados como indicadores de desempenho ambiental, o que reforça a escolha destes para a avaliação do desempenho ambiental das indústrias sucroalcooleiras.

Quadro 1 - Comparação entre indicadores de desempenho ambiental

\begin{tabular}{|c|c|c|c|c|c|c|c|c|c|c|}
\hline \multirow[b]{2}{*}{$\begin{array}{l}\text { CRITÉRIOS } \\
\text { AVALIADOS }\end{array}$} & \multicolumn{9}{|c|}{$\begin{array}{c}\text { INDICADORES DE DESEMPENHO } \\
\text { AMBIENTAL }\end{array}$} & \multirow[b]{2}{*}{$\begin{array}{l}\text { OUTROS AUTORES QUE CITAM OS } \\
\text { CRITÉRIOS AVALIADOS }\end{array}$} \\
\hline & $\underset{0}{0}$ & ฮี & 产 & $\underset{4}{\pi}$ & $\frac{\vec{\sigma}}{a}$ & $\sum_{\Sigma}^{\infty}$ & $\sum_{\mho}^{\$}$ & 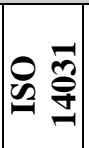 & 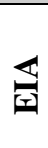 & \\
\hline $\begin{array}{l}\text { Mudanças no } \\
\text { Clima }\end{array}$ & $\mathrm{X}$ & & & & $\mathrm{X}$ & & & $\mathrm{X}$ & & $\begin{array}{l}\text { (Wiseman, 1982)(Lora, Palacio et al. 2011) } \\
\text { (Anastaselos, Giama et al. 2009) (Basurko and } \\
\text { Mesbahi) (Bonet-Ruiz, Bonet et al. 2010) } \\
\text { (McBride, Dale et al. 2011) (Renó, Lora et al. } \\
\text { 2011) (Sagastume Gutiérrez, Van Caneghem et } \\
\text { al. 2012) (Vince, Aoustin et al. 2008) }\end{array}$ \\
\hline $\begin{array}{l}\text { Camada de } \\
\text { ozônio }\end{array}$ & $\mathrm{X}$ & & & & $\mathrm{X}$ & & & & $\mathrm{X}$ & $\begin{array}{l}\text { (Wiseman, 1982) (Basurko and Mesbahi) } \\
\text { (Bonet-Ruiz, Bonet et al. 2010) (Renó, Lora et } \\
\text { al. 2011) (Vince, Aoustin et al. 2008) }\end{array}$ \\
\hline Qualidade do ar & $\mathrm{X}$ & & & $\mathrm{X}$ & & & & $\mathrm{X}$ & $\mathrm{X}$ & $\begin{array}{l}\text { (Wiseman, 1982) (Griffith and Bhutto 2009) } \\
\text { (Mauchline, Mortimer et al. 2012) (McBride, } \\
\text { Dale et al. 2011) (Purvis, Louwagie et al. 2009) } \\
\text { (Scipioni, Mazzi et al. 2009) }\end{array}$ \\
\hline $\begin{array}{l}\text { Geração de } \\
\text { resíduos }\end{array}$ & $\mathrm{X}$ & $\mathrm{X}$ & $\mathrm{X}$ & & $\mathrm{X}$ & & $\mathrm{X}$ & $\mathrm{X}$ & $\mathrm{X}$ & $\begin{array}{c}\text { (Wiseman, 1982) (Thoresen, 1999) (de } \\
\text { Figueirêdo, Rodrigues et al. 2010) (Scipioni, } \\
\text { Mazzi et al. 2009) }\end{array}$ \\
\hline $\begin{array}{l}\text { Qualidade da } \\
\text { água doce }\end{array}$ & $\mathrm{X}$ & & & $\mathrm{X}$ & & & & & $\mathrm{X}$ & $\begin{array}{l}\text { (Wiseman, 1982) (Bonet-Ruiz, Bonet et al. } \\
\text { 2010) (de Figueirêdo, Rodrigues et al. 2010) } \\
\text { (Griffith and Bhutto 2009) (Mauchline, } \\
\text { Mortimer et al. 2012) (McBride, Dale et al. } \\
\text { 2011) (Ou and Liu 2010) (Renó, Lora et al. } \\
\text { 2011) }\end{array}$ \\
\hline $\begin{array}{l}\text { Recursos da } \\
\text { água doce }\end{array}$ & $\mathrm{X}$ & $\mathrm{X}$ & $\mathrm{X}$ & $\mathrm{X}$ & $\mathrm{X}$ & & & & $\mathrm{X}$ & $\begin{array}{l}\text { (Wiseman, 1982) (de Figueirêdo, Rodrigues et } \\
\text { al. 2010) (Griffith and Bhutto 2009) (Mauchline, } \\
\text { Mortimer et al. 2012) (McBride, Dale et al. } \\
\text { 2011) (Ou and Liu 2010) (Renó, Lora et al. } \\
\text { 2011) (Scipioni, Mazzi et al. 2009) }\end{array}$ \\
\hline $\begin{array}{l}\text { Recursos } \\
\text { florestais }\end{array}$ & $\mathrm{X}$ & & $\mathrm{X}$ & & & & & & $\mathrm{X}$ & (Mauchline, Mortimer et al. 2012) \\
\hline $\begin{array}{l}\text { Recursos } \\
\text { pesqueiros }\end{array}$ & $\mathrm{X}$ & & $\mathrm{X}$ & & & & & & & (Ou and Liu 2010) \\
\hline $\begin{array}{l}\text { Recursos } \\
\text { energéticos }\end{array}$ & $\mathrm{X}$ & $\mathrm{X}$ & $\mathrm{X}$ & $\mathrm{X}$ & $\mathrm{X}$ & & $\mathrm{X}$ & $X$ & & $\begin{array}{l}\text { (Thoresen, 1999) (Lora, Palacio et al. 2011) } \\
\text { (Anastaselos, Giama et al. 2009) (Basurko and } \\
\text { Mesbahi) (Griffith and Bhutto 2009) } \\
\text { (Mauchline, Mortimer et al. 2012) (Sagastume } \\
\text { Gutiérrez, Van Caneghem et al. 2012) (Scipioni, } \\
\text { Mazzi et al. 2009) (Vince, Aoustin et al. 2008) }\end{array}$ \\
\hline
\end{tabular}




\begin{tabular}{|c|c|c|c|c|c|c|c|c|c|c|}
\hline & & & & & & & & & & (Wang, Xu et al. 2011) \\
\hline Biodiversidade & $\mathrm{X}$ & $\mathrm{X}$ & $\mathrm{X}$ & & $\mathrm{X}$ & & & & $\mathrm{X}$ & $\begin{array}{l}\text { (de Figueirêdo, Rodrigues et al. 2010) (Griffith } \\
\text { and Bhutto 2009) (Mauchline, Mortimer et al. } \\
\text { 2012) (McBride, Dale et al. 2011) (Ou and Liu } \\
\text { 2010) (Renó, Lora et al. 2011) }\end{array}$ \\
\hline Materiais & & $\mathrm{X}$ & & $\mathrm{X}$ & & & $\mathrm{X}$ & $\mathrm{X}$ & & (Thoresen, 1999) \\
\hline $\begin{array}{l}\text { Produtos e } \\
\text { serviços }\end{array}$ & & $\mathrm{X}$ & $\mathrm{X}$ & & $\mathrm{X}$ & $\mathrm{X}$ & $\mathrm{X}$ & $\mathrm{X}$ & & (Thoresen, 1999) \\
\hline Conformidade & & $\mathrm{X}$ & & & & & & $\mathrm{X}$ & & \\
\hline Transporte & & $\mathrm{X}$ & & & & & & $\mathrm{X}$ & $\mathrm{X}$ & (Thoresen, 1999) \\
\hline $\begin{array}{l}\text { Investimentos } \\
\text { em proteção } \\
\text { ambiental }\end{array}$ & & $\mathrm{X}$ & & & & & $\mathrm{X}$ & $\mathrm{X}$ & & \\
\hline $\begin{array}{l}\text { Impactos } \\
\text { ambientais }\end{array}$ & & & $\bar{X}$ & & & $\bar{X}$ & & $\bar{X}$ & $\mathrm{X}$ & $\begin{array}{c}\text { (Thoresen, 1999) (Lora, Palacio et al. 2011) } \\
\text { (Bonet-Ruiz, Bonet et al. 2010) (Griffith and } \\
\text { Bhutto 2009) }\end{array}$ \\
\hline $\begin{array}{l}\text { Restauração } \\
\text { ambiental }\end{array}$ & & & $\mathrm{X}$ & & & $\mathrm{X}$ & & & $\mathrm{X}$ & (Wiseman, 1982) \\
\hline $\begin{array}{l}\text { Divulgação de } \\
\text { informação } \\
\text { ambiental }\end{array}$ & & & $\mathrm{X}$ & & $\mathrm{X}$ & & & $\mathrm{X}$ & & \\
\hline $\begin{array}{l}\text { Gestão } \\
\text { responsável }\end{array}$ & & & $\mathrm{X}$ & $\mathrm{X}$ & $\mathrm{X}$ & & & $\mathrm{X}$ & & \\
\hline $\begin{array}{l}\text { Realização de } \\
\text { auditorias } \\
\text { ambientais e } \\
\text { relatórios }\end{array}$ & & & $\mathrm{X}$ & & $\mathrm{X}$ & $\mathrm{X}$ & $\bar{X}$ & $\mathrm{X}$ & & (Thoresen, 1999) \\
\hline $\begin{array}{l}\text { Política de } \\
\text { Gestão } \\
\text { Ambiental }\end{array}$ & & & & $\mathrm{X}$ & & $\bar{X}$ & $\bar{X}$ & $\mathrm{X}$ & & (Wiseman, 1982) (Thoresen, 1999) \\
\hline $\begin{array}{l}\text { Preparação para } \\
\text { emergências }\end{array}$ & & & & & & $\bar{X}$ & & $\mathrm{X}$ & & \\
\hline $\begin{array}{l}\text { Avaliação do } \\
\text { desempenho } \\
\text { global }\end{array}$ & & & & & & $\mathrm{X}$ & $\mathrm{X}$ & $\mathrm{X}$ & & \\
\hline $\begin{array}{l}\text { Avaliação de } \\
\text { oportunidades }\end{array}$ & & & & & & $\mathrm{X}$ & & & & \\
\hline $\begin{array}{l}\text { Estratégia para o } \\
\text { desenvolvimento } \\
\text { de tecnologias } \\
\text { ecologicamente } \\
\text { equilibradas }\end{array}$ & & & & & & $\mathrm{X}$ & $\mathrm{X}$ & $\mathrm{X}$ & & \\
\hline $\begin{array}{l}\text { Controle } \\
\text { operacional }\end{array}$ & & & & & & $\mathrm{X}$ & $\mathrm{X}$ & $\mathrm{X}$ & & (Wiseman, 1982) (Thoresen, 1999) \\
\hline $\begin{array}{l}\text { Consciência } \\
\text { ambiental do } \\
\text { consumidor }\end{array}$ & & & & & & & $\bar{X}$ & & & \\
\hline $\begin{array}{l}\text { Substância } \\
\text { químicas, } \\
\text { tóxicas e metais } \\
\text { pesados }\end{array}$ & & & & $\mathrm{X}$ & & & & & $\mathrm{X}$ & $\begin{array}{c}\text { (de Figueirêdo, Rodrigues et al. 2010) } \\
\text { (Sagastume Gutiérrez, Van Caneghem et al. } \\
\text { 2012) (Scipioni, Mazzi et al. 2009) (Wang, Xu } \\
\text { et al. 2011) }\end{array}$ \\
\hline $\begin{array}{l}\text { Alteração da } \\
\text { paisagem }\end{array}$ & & & & & & & & & $\mathrm{X}$ & $\begin{array}{l}\text { (Mauchline, Mortimer et al. 2012) (Ou and Liu } \\
\text { 2010) }\end{array}$ \\
\hline $\begin{array}{l}\text { Impacto sobre o } \\
\text { solo, por meio } \\
\text { da compactação } \\
\text { e uso intensivo } \\
\text { de adubos e } \\
\text { herbicidas }\end{array}$ & & & & & & & & & $\mathrm{X}$ & $\begin{array}{l}\text { (Anastaselos, Giama et al. 2009; McBride, Dale } \\
\text { et al. 2011) (Basurko and Mesbahi) (Bonet-Ruiz, } \\
\text { Bonet et al. 2010) (de Figueirêdo, Rodrigues et } \\
\text { al. 2010) (Griffith and Bhutto 2009) (Mauchline, } \\
\text { Mortimer et al. 2012) (Ou and Liu 2010) } \\
\text { (Sagastume Gutiérrez, Van Caneghem et al. } \\
\text { 2012) (Vince, Aoustin et al. 2008) }\end{array}$ \\
\hline $\begin{array}{l}\text { Emissão de } \\
\text { fuligem e forte }\end{array}$ & & & & & & & & & $\mathrm{X}$ & \\
\hline
\end{tabular}




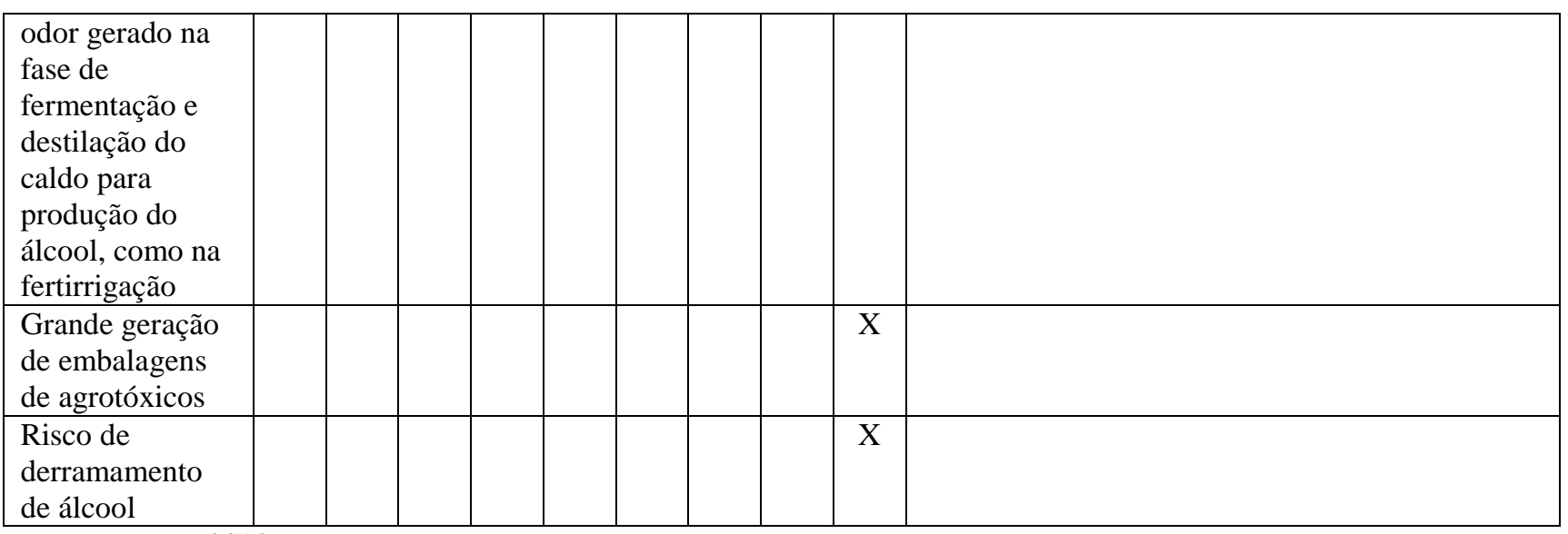

Fonte: Raupp, 2012

Observa-se que os indicadores, OECD, CERES, DJSI e a ISO 14031 possuem uma abordagem muito parecida, estando focados na questão da preocupação com o aquecimento global, emissões de Gases de Efeito Estufa, recursos hídricos, energéticos, gestão de resíduos, preocupação com os impactos gerados e como as empresas divulgam e tratam dessas questões, entre outros.

Os indicadores MAIS e GAIA são mais focados na questão gerencial da questão ambiental, mais voltados às características da ISO 14001, legislação ambiental, ou seja, ao Sistema de Gestão Ambiental da empresa.

Já os indicadores dos EIAs possuem uma relação com os indicadores da OECD, GRI, CERES, EPA, DJSI e ISO 14031, além das características particulares do empreendimento.

\section{Método de pesquisa}

Neste trabalho o desenvolvimento da revisão de literatura foi através de pesquisa bibliográfica e documental em livros, artigos, sites da Internet e bibliométrica, que possibilitaram o acesso a vários manuais e informações recentes existentes no Brasil e no mundo sobre desempenho ambiental, indústrias sucroalcooleiras e indicadores de desempenho ambiental.

Esta revisão bibliográfica auxiliou na elaboração do questionário que foi encaminhado para as indústrias sucroalcooleiras, que indicaram se os critérios eram pertinentes ou não ao setor.

Como este trabalho propõe um novo modelo de indicadores de desempenho ambiental, o método de estudo de caso é adequado, pois irá investigar os detalhes de sua aplicação nas indústrias sucroalcooleiras, comparar os resultados e oferecer informações que possam transformá-lo em algo adequado à realidade deste setor.

Como método de coleta de dados, foi utilizado um questionário aberto, para que as empresas pudessem comentar sobre os indicadores que foram sugeridos pela pesquisa, quanto a sua pertinência ou não. 


\section{Determinação de indicadores de desempenho ambiental para as indústrias sucroalcooleiras}

Para determinar estes indicadores, foi realizado um cruzamento dos critérios de avaliação do desempenho ambiental de todos os modelos pesquisados, conforme apresentado no Quadro 1. Após se chegar a pontos de convergência e importância de alguns critérios, foram desenvolvidas perguntas que foram utilizadas para avaliar o desempenho ambiental das indústrias sucroalcooleiras. Assim, o questionário foi encaminhado para duas empresas do setor sucroalcooleiro para que verificassem a importância e aplicabilidade dos indicadores. Com a resposta das empresas, foi desenvolvido um conjunto de indicadores para avaliar o desempenho ambiental das indústrias sucroalcooleiras, conforme Quadro 2, que com as considerações das 2 empresas participantes foi alterado e encaminhado para todas as 22 empresas instaladas no Estado do Mato Grosso do Sul, onde apenas 11 obtiveram liberação para informar se as perguntas eram pertinentes ao setor.

Quadro 2 - Conjunto de indicadores de desempenho ambiental da indústria sucroalcooleira

\begin{tabular}{|c|c|c|}
\hline & Critérios avaliados & Perguntas: A empresa possui: \\
\hline & Mudanças no Clima & $\begin{array}{l}\text { 1. Algum registro/controle de índices de emissão de Gases } \\
\text { de Efeito Estufa (GEE)? }\end{array}$ \\
\hline & Camada de ozônio & $\begin{array}{l}\text { 2. Algum registro/controle de consumo de substâncias que } \\
\text { afetam a camada de ozônio? }\end{array}$ \\
\hline & Qualidade do ar & $\begin{array}{l}\text { 3. Algum registro/controle da intensidade de emissão de } \\
\text { poluentes? }\end{array}$ \\
\hline & Geração de resíduos & $\begin{array}{l}\text { 4. Registro/controle da intensidade da geração de resíduos } \\
\text { de efluentes? } \\
\text { 5. Registro/controle da intensidade da geração de } \\
\text { embalagens de agrotóxicos? }\end{array}$ \\
\hline & Qualidade da água doce & 6. Tratamento de águas residuais? \\
\hline & Recursos da água doce & $\begin{array}{l}\text { 7. Algum registro/controle da intensidade de utilização } \\
\text { dos recursos hídricos? }\end{array}$ \\
\hline 它 & Recursos florestais & $\begin{array}{l}\text { 8. Registro/controle da intensidade de utilização dos } \\
\text { recursos florestais? }\end{array}$ \\
\hline 勻 & Recursos energéticos & $\begin{array}{l}\text { 9. Registro/controle da intensidade de utilização de } \\
\text { energia? }\end{array}$ \\
\hline $\begin{array}{l}\sum_{2} \\
0 \\
0 \\
1\end{array}$ & Biodiversidade & $\begin{array}{l}\text { 10. Registro/controle da quantidade de espécies ameaçadas } \\
\text { que se encontram dentro das áreas da empresa ou } \\
\text { influenciado por esta? }\end{array}$ \\
\hline$\sum_{i=1}^{10}$ & Materiais & $\begin{array}{l}\text { 11. Registro/controle de materiais usados por peso ou } \\
\text { volume de adubos e agrotóxicos utilizados? }\end{array}$ \\
\hline 剀 & $\begin{array}{l}\text { Conformidade com } \\
\text { normas ambientais }\end{array}$ & $\begin{array}{l}\text { 12. A empresa conhece os impactos ambientais causados? } \\
\text { 13. A O valor monetário de multas significativas e o } \\
\text { número total de sanções não-monetárias resultantes da } \\
\text { não conformidade com leis e regulamentos ambientais? }\end{array}$ \\
\hline & Transporte & $\begin{array}{l}\text { 14. A empresa reconhece os impactos ambientais } \\
\text { resultantes do transporte? } \\
\text { 15. Alguma iniciativa para minimizar os impactos } \\
\text { ambientais resultantes do transporte de produtos, bens, } \\
\text { materiais utilizados nas operações da organização, bem } \\
\text { como do transporte de trabalhadores? }\end{array}$ \\
\hline & $\begin{array}{l}\text { Investimentos em } \\
\text { proteção ambiental }\end{array}$ & $\begin{array}{l}\text { 16. A empresa faz algum tipo de investimento e gastos com } \\
\text { proteção ambiental? }\end{array}$ \\
\hline & Impactos ambientais & 17. Iniciativa para mitigar os impactos ambientais gerados? \\
\hline & $\begin{array}{l}\text { Divulgação de } \\
\text { informação ambiental }\end{array}$ & $\begin{array}{l}\text { 18. Iniciativa de divulgação de informação ambiental, como } \\
\text { informar em tempo hábil a todos que podem ser } \\
\text { afetados por condições provocadas pela empresa que }\end{array}$ \\
\hline
\end{tabular}




\begin{tabular}{|c|c|}
\hline & $\begin{array}{l}\text { possam comprometer a saúde, a segurança ou o } \\
\text { ambiente? }\end{array}$ \\
\hline Gestão responsável & $\begin{array}{l}\text { 19. A empresa mantém diálogos com as pessoas e } \\
\text { comunidades afetadas? } \\
\text { 20. A alta administração da empresa está preocupada com } \\
\text { os princípios ambientais da empresa? }\end{array}$ \\
\hline $\begin{array}{l}\text { Realização de } \\
\text { auditorias ambientais e } \\
\text { relatórios }\end{array}$ & $\begin{array}{l}\text { 21. A empresa mantêm como prática a realização de } \\
\text { auditorias ambientais e divulgação de relatórios? }\end{array}$ \\
\hline $\begin{array}{l}\text { Política de Gestão } \\
\text { Ambiental }\end{array}$ & $\begin{array}{l}\text { 22. Uma Política de Gestão Ambiental?. } \\
\text { 23. Algum tipo de trabalho com educação e conscientização } \\
\text { ambiental? }\end{array}$ \\
\hline $\begin{array}{l}\text { Preparação para } \\
\text { emergências/ Risco de } \\
\text { derramamento de álcool }\end{array}$ & 24. A empresa prepara os funcionários para emergências? \\
\hline $\begin{array}{l}\text { Avaliação do } \\
\text { desempenho global }\end{array}$ & $\begin{array}{l}\text { 25. A empresa avalia seu desempenho global, considerando } \\
\text { o meio ambiente? }\end{array}$ \\
\hline $\begin{array}{l}\text { Estratégia para o } \\
\text { desenvolvimento ou } \\
\text { aplicações de } \\
\text { tecnologias } \\
\text { ecologicamente } \\
\text { equilibradas }\end{array}$ & $\begin{array}{l}\text { 26. Alguma estratégia para o desenvolvimento ou } \\
\text { aplicações de tecnologias ecologicamente equilibradas? } \\
\text { Quais? }\end{array}$ \\
\hline Controle operacional & 27. Controle operacional? \\
\hline $\begin{array}{l}\text { Consciência ambiental } \\
\text { do consumidor }\end{array}$ & $\begin{array}{l}\text { 28. A empresa conhece a consciência ambiental do seu } \\
\text { consumidor? }\end{array}$ \\
\hline $\begin{array}{l}\text { Substância químicas e } \\
\text { tóxicas }\end{array}$ & $\begin{array}{l}\text { 29. Durante todo o processo é utilizado algum tipo de } \\
\text { substâncias químicas e tóxicas? }\end{array}$ \\
\hline Alteração da paisagem & $\begin{array}{l}\text { 30. Com a implantação da usina na região, existe alguma } \\
\text { preocupação com a alteração da paisagem? } \\
\text { 31. A empresa se preocupa com a compactação do solo e o } \\
\text { uso de adubos e herbicidas? }\end{array}$ \\
\hline $\begin{array}{l}\text { Emissão de fuligem e } \\
\text { odor }\end{array}$ & $\begin{array}{l}\text { 32. Existe algum tipo de programa que se preocupe com o } \\
\text { odor gerado na fase de fermentação e destilação para } \\
\text { produção do álcool? } \\
\text { 33. A empresa se preocupa com a emissão de fuligem? }\end{array}$ \\
\hline
\end{tabular}

Fonte: Raupp, 2012

\section{Conclusões}

O controle da questão ambiental é importante para todas as empresas, principalmente as que estão relacionadas a recursos não renováveis e a agricultura, pois elas dependem do bom andamento destes. Para que se saiba como estão estas questões ambientais, é necessário ter conhecimento do que é importante e impactante para cada empresa, para que se possa controlar, diminuir ou reduzir.

Como foi abordado acima, os indicadores devem ser flexíveis e adaptáveis as indústrias, para que elas possam entender as informações que eles podem trazer. Partindo disso, foi que este trabalho desenvolveu-se, criando uma forma de avaliar o desempenho ambiental das indústrias sucroalcooleiras.

O objetivo deste trabalho foi de determinar indicadores de desempenho ambiental para as indústrias sucroalcooleiras, sendo que este foi alcançado, como apresentado no Quadro 2, que apresenta 33 questões que permitem indicar o desempenho ambiental destas indústrias. Estes indicadores são o resultado do cotejamento dos principais indicadores de desempenho ambiental 
pesquisados e os impactos ambientais causados por estas empresas, apresentados nos EIA, além da verificação destas ações que são aplicadas em artigos mais recentes.

O envio de um questionário que abordava todas as ações propostas para avaliar o desempenho ambiental das empresas foi fundamental para a confirmação de sua relevância, pois somente desta forma pode-se criar o modelo para avaliar o desempenho ambiental das indústrias sucroalcooleiras.

\section{Abstract}

The relationship between companies and the environment has shown that the environmental impacts of the production activities are compromising the future of the planet. The way that companies see the environmental issues and plan their development is extremely important for their survival and conservation of the environment. The sugarcane sector is recognized as one of the most environment impacting. The objective of this paper is to propose environmental performance indicators that can be applied in the sugarcane industries. The study was based on a literature and bibliometric indicators of environmental performance and after the crossing between them to check points of convergence. In a second step we designed a questionnaire that was sent to the companies with the selected indicators, so they verify their applicability in the industry. With the response were determined environmental performance indicators for the sugar and alcohol industries.

Key-words: Sustainable Development, Performance Indicators, Sugarcane Industry.

\section{REFERÊNCIAS BIBLIOGRÁFICAS}

ABNT NBR ISO 14.001. Sistema de gestão ambiental. ABNT, 2004.

ABNT NBR ISO 14.031. Gestão Ambiental - avaliação de desempenho ambiental - diretrizes. ABNT, 2004.

ANASTASELOS, D., E.; GIAMA, et al. An assessment tool for the energy, economic and environmental evaluation of thermal insulation solutions. Energy and Buildings, 2009.

BASURKO, O. C.; MESBAHI E. Methodology for the sustainability assessment of marine technologies. Journal of Cleaner Production, 2012.

BONET-RUIZ, A. E., BONET, J. et al. Environmental performance assessment for reactive distillation processes. Resources, Conservation and Recycling, 2010. crossref

BRASIL. MINISTÉRIO DO MEIO AMBIENTE. Dispõe sobre critérios básicos e e diretrizes gerais para a avaliação de impacto ambiental. Resolução n. 001, de 23 de janeiro de 1986. Conselho Nacional do Meio Ambiente. Disponível em: http://www.antt.gov.br/legislacao/Regulacao/suerg/Res001-86.pdf. Acesso em: 11 out. 2011.

CARTILHA FIESP-CIESP. Indicadores de desempenho ambiental da indústria. 2003. Disponível em: http://www.fiesp.com.br/ download/publicacoes_meio_ambiente/ cartilha_indic_ambiental.pdf. Acesso em: 13 fev. 2011.

CEBDS - Conselho Empresarial Brasileiro para o Desenvolvimento Sustentável. Guia de produção mais limpa: faça você mesmo. Disponível em: 〈http://www.pmaisl.com.br/publicacoes/guiadepmaisl/guia-da-pmaisl.pdf〉. Acesso em: 03 ago. 2006.

CERES. Ceres Principles - Corporate Environmental Conduct. Disponível em: www.ceres.org/Page.aspx?pid=416 Acesso em: 24 out. 2009. 
CORAL, E. Modelo de planejamento estratégico para a sustentabilidade empresarial. 2002. 275 f. Tese Engenharia da Produção e Sistemas, Universidade Federal de Santa Catarina, Florianópolis, 2002.

FIGUEIRÊDO, M. C. B.; RODRIGUES, G. S. et al. Environmental performance evaluation of agro-industrial innovations - Part 2: methodological approach for performing vulnerability analysis of watersheds. Journal of Cleaner Production, 2010.

DONAIRE, D. Gestão ambiental na empresa. 2. ed. São Paulo: Atlas, 1999.

DONATO, V. Logística Verde. Rio de Janeiro: Editora Ciência Moderna Ltda., 2008.

DOW JONES. Dow Jones Sustentability Index. 2009. Disponível em: www.sustainability-indexes.com. Acesso em: 20 jan. 2010.

ENVIRONMENTAL PROTECTION AGENCY US. Environmental management system implementation: Guide for shipbuilding and ship repair industry, 2003. Disponível em:

http://www.epa.gov/sustainableindustry/shipbuilding/module_05.pdf. Acesso em: 06 out. 2011.

ESTY, D. C. O verde que vale ouro: como empresas inteligentes usam a estratégia ambiental para inovar, criar valor e construir uma vantagem competitiva. Rio de Janeiro: Elsevier, 2008.

GALLARDO, A. L. C. F.; BOND, A. Capturing the implications of land use change in Brazil through environmental assessment: Time for a strategic approach? Environmental Impact Assessment Review, 2010.

GASPARINI, L. V. L. Análise das inter-relações de indicadores econômicos, ambientais e sociais para o desenvolvimento sustentável. 2003. 221 f. Dissertação - Engenharia de Produção e Sistemas, Universidade Federal de Santa Catarina, Florianópolis, 2003.

GIRARDIN, P., BOCKSTALLER, C., WERF, H. Van der. Assessment of potential impacts of agricultural practices on the environment: the AGRO*ECO method. Environmental Impact Assessment Review, n. 20, 2000.

GLOBAL REPORTING INITIATIVE. Sustentablility Reporting Guidelines. 2008. Disponível em: www.globalreportinginitiative.org.br. Acesso em: 10 jan. 2010.

GRIFFITH, A., BHUTTO, K. Better environmental performance: A framework for integrated management systems (IMS). Management of Environmental Quality, 2009. crossref

HRONEC, S. M. Sinais Vitais. São Paulo: Makron Books, 1994.

INTERNATIONAL ASSOCIATION FOR IMPACTS ASSESSMENT - IAIA. Principles of Environmental Impact Assessment: best practice. 1999. Disponível em: http://www.iaia.org/publicdocuments/specialpublications/Principles\%20of\%20IA_web.pdf. Acesso em: 11 de out de 2011.

LERIPIO, A. de Á.. GAIA - um método de gerenciamento de aspectos e impactos ambientais. Tese de Doutorado. Florianópolis: UFSC, 2001.

LORA, E. E. S.; PALACIO, J. C. E., et al. Issues to consider, existing tools and constraints in biofuels sustainability assessments. Energy, 2011.

LORA, Electro Silva. Prevenção e controle da poluição nos setores energético, industrial e de transporte. Brasília, DF: ANEEL, 2000.

MANFINATO, W., ROCHA, M. T.. O agronegócio da cana e as mudanças do clima - algumas implicações da convenção do clima sobre o setor sucroalcooleiro. Disponível em: http://www.udop.com.br/index.php?item=noticias\&cod=26283. Acesso em: 28 jan. 2010.

MARTINS, R. A.; COSTA NETO, P. L. de O. Indicadores de desempenho para a gestão pela qualidade total: uma proposta de sistematização. Revista Gestão e Produção, v.5, n.3, 1998.

MAUCHLINE, A. L.; MORTIMER, S. R., et al. Environmental evaluation of agri-environment schemes using participatory approaches: Experiences of testing the Agri-Environmental Footprint Index. Land Use Policy, 2012. crossref 
MCBRIDE, A. C.; DALE, V. H., et al. Indicators to support environmental sustainability of bioenergy systems. Ecological Indicators, 2011. cross ref

MOREIRA, I. V. D.. Avaliação de impacto ambiental - AIA. Assessoria Técnica da Presidência. FEEMA: Rio de Janeiro, 1985. Disponível em: http://www.uff.br/estudossociaisambientais/Avadeimpactoambiental.doc. Acesso em: 21 de set. 2011.

NEVES, M. F. Agronegócio e desenvolvimento sustentável: uma agenda para a liderança mundial na produção de alimentos e bioenergia. São Paulo: Atlas, 2009.

OECD. Key environmental indicators. Paris, 2008

OLIVEIRA, J. H. R. MAIS: Método para Avaliação de Indicadores de Sustentabilidade Organizacional. Tese de Doutorado. Florianópolis: UFSC, 2002.

OU, C.-H.,LIU, W.-H. Developing a sustainable indicator system based on the pressure-state-response framework for local fisheries: A case study of Gungliau, Taiwan. Ocean \&amp; Coastal Management, 2010. cross ref

PIACENTE, F. J. A Agroindústria canavieira e o sistema de Gestão das Usinas Localizadas nas Bacias Hidrográficas dos Rios Piracicaba, Capivari e Jundiaí, 2005. 181 f. Dissertação (Mestrado em Ciências Econômicas); Unicamp, Campinas: Unicamp, 2005.

PURVIS, G., LOUWAGIE, G., et al. Conceptual development of a harmonised method for tracking change and evaluating policy in the agri-environment: The Agri-environmental Footprint Index. Methodology for the sustainability assessment of marine technologies, 2009.

RAUPP, F. Modelo de autoavaliação do desempenho ambiental para a agroindústria - o caso da indústria sucroalcooleira do Mato Grosso do Sul. Tese de Doutorado. Florianópolis: UFSC, 2012.

RENÓ, M. L. G.; LORA, E. E. S., et al. A LCA (life cycle assessment) of the methanol production from sugarcane bagasse. Energy, 2011. cross ref

SABADIN, C.; GONÇALVES, E. V.. Estudo da cadeia produtiva do açúcar e do álcool no Estado do Mato Grosso do Sul. Campo Grande: 2005. Disponível em: fcr.org. br/estudousinas/docs/estudo-cadeia-cana.doc. Acesso em: 28 jan. 2010.

SAGASTUME GUTIÉRREZ, A., VAN CANEGHEM, J., et al. Evaluation of the environmental performance of lime production in Cuba. Journal of Cleaner Production. 2012. cross ref

SÁNCHEZ, L. E. Avaliação de impacto ambiental: conceitos e métodos. São Paulo: Oficina de Textos, 2008.

SCIPIONI, A., MAZZI, A., et al. The Dashboard of Sustainability to measure the local urban sustainable development: The case study of Padua Municipality. Ecological Indicators, 2009. crossref

SILVA, A. F.; FERREIRA, A. C. de S.. Um estudo sobre a contabilização dos impactos ambientais no setor sucroalcooleiro. Anais do Congresso USP de Controladoria e Contabilidade. São Paulo: São Paulo, 2009. Disponível em: http://www.congressousp.fipecafi.org/artigos92009/495.pdf. Acesso em: 21 de set. 2011.

STAMM, H. R.. Método para avaliação de impacto ambiental (AIA) em projetos de grande porte: estudo de caso de uma usina termelétrica. Tese de doutorado. Florianópolis: UFSC, 2003.

STROBEL, J. S. Modelo para a mensuração da sustentabilidade corporativa através de indicadores. Dissertação de mestrado. Florianópolis: UFSC, 2004.

THORESEN, J..Environmental performance evaluation - a tool for industrial improvement. Journal of Cleaner Production, 1999. crossref

TRINDADE, S. P.; CHAVES, M. R.. Sustentabilidade do setor sucroalcooleiro em Goiás: relação da produção agrícola e impactos ambientais. Anais do V Simpósio Nacional de Geografia Agrária. Universidade Federal Fluminense Niterói - RJ, 2009. Disponível em: www.uff.br/vsinga/trabalhos/.../Silas\%20Pereira\%20Trindade.pdf. Acesso em: 21 de set. 2011. 
UDOP - União dos produtores de bioenergia. A sustentabilidade no setor da bioenergia. Disponível em: http://www.udop.com.br/index.php?item=sustentabilidade. Acesso em: 28 jan. 2010.

UNIÃO DA INDÚSTRIA DE CANA-DE-AÇÚCAR. A indústria da cana-de-açúcar: etanol, açúcar e bioeletricidade. São Paulo, 2008.

VAN BELLEN, H. M. Indicadores de Sustentabilidade: uma análise comparativa. Rio de Janeiro: Editora FGV, 2006.

VINCE, F.; AOUSTIN, E., et al. LCA tool for the environmental evaluation of potable water production. Desalination, 2008. crossref

WANG, L.; XU, L., et al. Environmental performance evaluation of Beijing's energy use planning. Energy Policy, 2011. cross ref

WISEMAN, J.. An evaluation of environmental disclosures made in corporate annual reports. Accounting, Organizations and Society, v. 7, n. 1, p. 53-63, Printed in Great Britain, 1982.

\section{Dados dos autores:}

\section{Nome completo: Fabiana Raupp}

Filiação institucional: UFGD - Faculdade de Engenharia

Endereço completo para correspondência (bairro, cidade, estado, país e CEP): Rodovia Dourados Itahum, Km 12 - Cidade Universitária. Caixa Postal 533 - CEP: 79.804-970

Telefone: (67) 3410-2172

e-mail: fabianaraupp@gmail.com

\section{Nome completo: Paulo Maurício Selig}

Filiação institucional: Universidade Federal de Santa Catarina - Programa de Pós-graduação em Engenharia e Gestão do Conhecimento

Departamento: Engenharia e Gestão do Conhecimento

Função ou cargo ocupado: Professor Voluntário (Aposentado)

Endereço completo para correspondência (bairro, cidade, estado, país e CEP): Campus

Universitário Reitor João David Ferreira Lima, Trindade, Florianópolis - Santa Catarina, 88040-900

Telefone: (48) 3721-9000

e-mail:pauloselig@gmail.com

\section{Nome completo: Eduardo Juan Soriano-Sierra}

Filiação institucional: Universidade Federal de Santa Catarina

Departamento: Departamento de Ecologia e Zoologia

Endereço completo para correspondência (bairro, cidade, estado, país e CEP): Campus

Universitário Reitor João David Ferreira Lima, Trindade, Florianópolis - Santa Catarina, 88040-900 
Telefone: (48) 3721-9000

e-mail: sierra_ejs@yahoo.com.br

Submetido em: 14/02/2014

Aceito em: 18/12/2014 